\title{
Sequential neurological improvements after conservative treatment in patients with complete motor paralysis caused by cervical spinal cord injury without bone and disc injury
}

\author{
Eiji Mori, MD, ${ }^{1}$ Takayoshi Ueta, MD, PhD, ${ }^{1}$ Takeshi Maeda, MD, PhD, ${ }^{1}$ Ryousuke Ideta, ${ }^{2}$ \\ Itaru Yugué, MD, PhD, ${ }^{1}$ Osamu Kawano, MD, PhD, ${ }^{1}$ and Keiichiro Shiba, MD, PhD'1 \\ Departments of ${ }^{1}$ Orthopaedic Surgery and ${ }^{2}$ Rehabilitation Medicine, Japan Organization of Occupational Health and Safety, \\ Spinal Injuries Center, Igisu, lizuka, Fukuoka, Japan
}

OBJECTIVE This study investigated neurological improvements after conservative treatment in patients with complete motor paralysis caused by acute cervical spinal cord injury (SCI) without bone and disc injury.

METHODS This study was retrospective. The authors evaluated neurological outcomes after conservative treatment of 62 patients with complete motor paralysis caused by cervical SCI without bone and disc injury within 72 hours after trauma. The sequential changes in their American Spinal Injury Association Impairment Scale (AIS) grades were reviewed at follow-up 24-72 hours, 1 week, and 1, 3, and 6 months after treatment.

RESULTS Of the 31 patients with a baseline AIS grade of A, 2 (6.5\%) patients improved to grade B, 5 (16.1\%) improved to grade C, and $2(6.5 \%)$ improved to grade D by the 6-month follow-up. The $22(71.0 \%)$ patients who remained at AIS grade A 1 month after injury showed no neurological improvement at the 6-month follow-up. Of the 31 patients with a baseline AIS grade of B, $12(38.7 \%)$ patients showed at least a 1-grade improvement at the 1-month follow-up; 11 (35.5\%) patients improved to grade $C$ and $16(51.6 \%)$ patients improved to grade $D$ at the 6 -month follow-up.

CONCLUSIONS Even in patients with complete motor paralysis caused by cervical $\mathrm{SCl}$ without bone and disc injury within 72 hours after trauma, approximately $30 \%$ of the patients with an AIS grade of A and $85 \%$ of the patients with an AIS grade B improved neurologically after conservative treatment. It is very important to recognize the extent of neurological improvement possible with conservative treatment, even for severe complete motor paralysis.

https://thejns.org/doi/abs/10.3171/2017.10.SPINE17844

KEYWORDS cervical spinal cord injury without bone and disc injury; conservative treatment; neurological improvement; complete motor paralysis; ASIA Impairment Scale

$\mathrm{C}$ ERVICAL spinal cord injury (SCI) without bone and disc injury tends to be caused mainly by hyperextension force to the neck. ${ }^{29}$ Most patients with such injury are elderly and have a radiographic abnormality such as osteophytes, disc bulging/herniation, or hypertrophy of the ligamentum flavum and might present with quadriplegia caused by hyperextension injury. ${ }^{19,20,28,35}$ Whether this injury should be treated with surgery or conservative measures remains controversial. ${ }^{3-5,8,15-17,25,27,31,36}$ When MRI reveals spinal cord compression associated with spinal canal stenosis, decompression surgery can be indicated. Some surgeons argue in favor of early surgical decompres- sion in the setting of SCI, because decompression surgery within 24 hours has resulted in improved outcomes when compared with delayed decompression, $, 922,23$ whereas other investigators reported that surgical timing made no difference in neurological outcomes. ${ }^{1,12,31}$ The surgical timing for this injury remains controversial in terms of neurological results. In patients who experience a complete loss of lower-extremity motor function, defined as American Spinal Injury Association (ASIA) impairment scale (AIS) grade $A$ or $B,{ }^{18}$ within $24-72$ hours after the cervical SCI, the appearance of lower-extremity motion after surgical intervention seems to demonstrate the effectiveness of surgery.

ABBREVIATIONS AIS = ASIA Impairment Scale; ASIA = American Spinal Injury Association; $\mathrm{SCl}=$ spinal cord injury .

SUBMITTED July 30, 2017. ACCEPTED October 18, 2017.

INCLUDE WHEN CITING Published online April 20, 2018; DOI: 10.3171/2017.10.SPINE17844. 
However, some patients who could have experienced a spontaneous recovery would have already been subjected to surgery. It is not difficult to understand that patients with acute AIS grade C cervical SCI can recover as a result of the natural course because at AIS grade $\mathrm{C}$, motor paralysis is incomplete. Even among patients with acute cervical SCI associated with complete motor paralysis (AIS grade A or B), some patients can be expected to recover spontaneously after conservative treatment. The purpose of our study was to investigate sequential neurological improvements after conservative treatment in patients with complete loss of lower-extremity motor function within 72 hours after cervical SCI without bone and disc injury.

\section{Methods}

Acute traumatic cervical SCI without bone and disc injury often is described as SCI without a radiographic abnormality in adults,,${ }^{19,35} \mathrm{SCI}$ without radiographic evidence of trauma, ${ }^{20,28}$ or cervical SCI without bony injury ${ }^{13}$ that includes disc injury, small avulsion fracture of the vertebral body, spinous process fracture, or other ligamentous injury. We considered cervical SCI with or without those injuries but without fracture, dislocation, and spinal canal bony injury, such as tear-drop fracture or facet fracture, as traumatic cervical SCI without bone and disc injury. We carefully examined flexion-extension lateral radiographs obtained by spine surgeons at the time of patient admission using a Roentgen fluoroscope to evaluate potential instability. Posterior translation of the cephalad vertebral body at the site of injury was included in the radiographic study of patients with this kind of injury, but spontaneously reduced flexion-distraction injury (recoil flexion injury), ${ }^{2}$ which appears as abnormal local kyphosis and slippage of the injured segment, was excluded in the differential diagnosis.

In total, 188 patients with cervical SCI without bone and disc injury were admitted to our hospital within 72 hours after injury between June 2005 and June 2014. Our principal treatment measures for cervical SCI without bone and disc injury have been conservative and included performing rehabilitation with the patient wearing a simple cervical collar for 3 to 4 weeks beginning at admission; therefore, we have not used surgical treatment for this kind of injury. In these patients, we performed a careful neurological examination based on the ASIA classification of the SCI at the time of admission. According to the AIS, grade A indicates that no sensory or motor function is preserved in sacral segments S4-5, whereas grade B indicates that sensory but not motor function is preserved below the neurological level and includes the sacral segments and that no motor function is preserved more than 3 levels below the motor level..$^{18}$ We defined patient injuries as either AIS grade A or B when no motor function of the lower extremity as a result of cervical SCI was found. The ethics committee of our institution approved the study.

Seventy-four patients had complete motor paralysis (AIS grade A or B) at the time of admission, and 62 patients underwent follow-up examinations for more than 6 months after they received conservative treatment. The remaining 114 patients who had incomplete motor paralysis and 12 patients who had complete motor paralysis with a short follow-up period were excluded. One of these 12 patients died as a result of pneumonia a few days after injury, 2 patients were transferred to another hospital because of their poor general condition, and 9 patients were moved voluntarily to another hospital within a few months after admission. Of the 62 patients included in our study, 54 were men, and 8 were women, and their mean age was 64.9 years (range 22-88 years). Various environmental factors, such as the occupations, sports activities, and alcohol preferences of men, might have influenced the marked male predominance and their susceptibility to this sort of injury. The distribution of AIS grades among these patients at the time of admission is summarized in Table 1.

A total of 62 patients were admitted to our hospital within 72 hours after injury, and none of them showed leg motor function at the time of admission. Twelve of the 62 patients were transferred directly to our hospital from the accident scene within 24 hours after injury; 5 of those patients had AIS grade A SCI and 7 had AIS grade B SCI. The remaining 50 patients were transferred from primary institutions. We were unable to obtain information about their precise neurological status, except that they were not capable of voluntary leg movements immediately after injury, because the doctors at the primary institutions were unfamiliar with the ASIA neurological evaluation. Of the 31 patients who had AIS grade B SCI, 4 seemed to have complete motor and sensory paralysis immediately after injury as assessed by the doctors at the primary institution. Among the patients who were admitted within 48 hours after injury, some recovered to AIS grade $\mathrm{C}$ within 25-72 hours; those patients, however, were still classified initially as having a baseline AIS grade of A or B. Complete motor paralysis within 72 hours after injury indicated a baseline AIS grade of A or B at the time of admission but does not indicate that patients remained with complete motor paralysis until 72 hours after injury. We intended to analyze sequential neurological changes from AIS grade $\mathrm{A}$ or $\mathrm{B}$ at the time of admission during the follow-up period, including within 72 hours after injury.

\section{TABLE 1. Population demographics}

\begin{tabular}{|c|c|}
\hline Variable & Value \\
\hline No. of patients & 62 \\
\hline Mean age in yrs (range) & $64.9(22-88)$ \\
\hline Sex (male/female) & $54: 8$ \\
\hline Mean follow-up in mos (range) & $10.2(6-36)$ \\
\hline \multicolumn{2}{|c|}{ AIS grade at different time points after admission in hrs } \\
\hline \multicolumn{2}{|c|}{ A } \\
\hline$<24$ & 14 \\
\hline $24-48$ & 13 \\
\hline $48-72$ & 4 \\
\hline \multicolumn{2}{|l|}{$\mathrm{B}$} \\
\hline$<24$ & 18 \\
\hline $24-48$ & 6 \\
\hline $48-72$ & 7 \\
\hline
\end{tabular}

Values represent numbers of patients unless otherwise indicated. 
The AIS was used to evaluate the patients' neurological outcomes. The examination was performed on admission and then repeated 48 hours, 72 hours, 1 week, 1 month, 3 months, and 6 months after injury to assess sequential neurological improvements after conservative treatment. To assess the patients with an AIS grade B injury, we used our own modified Frankel grade. ${ }^{14}$ Patients with a modified Frankel grade of B were placed into 1 of 3 subgroups: grade B1 indicated that the ability to feel light touch was preserved only in sacral segments $\mathrm{S} 4-5$, grade B2 indicated that the ability to feel light touch was preserved below the neurological level, and grade B3 indicated that the ability to feel a pinprick was preserved in sacral segments S45 . The examinations were performed by 2 medical doctors who were in charge of the patients at their admission. When the physicians made different decisions regarding the AIS grade, a final decision was made after discussion.

We also evaluated spinal cord compression associated with preexisting spinal canal stenosis at the injured level with midsagittal MRI. The spinal cord compression rate (percentage) was calculated as follows: (diameter of the cervical cord at the noncompression level - diameter of the cervical cord at the injured level) $\times 100$ /diameter of the cervical cord at the noncompression level. ${ }^{16}$ Most patients had an injury at the C3-4 or C4-5 segments (80.6\%); therefore, the C-6 or C-7 vertebral body level was chosen as the noncompression level. One medical doctor who was blind to the patients' clinical diagnosis determined the compression rate 2 times and obtained an average. Based on the criteria of White et al. ${ }^{37}$ posterior translation of more than $3.5 \mathrm{~mm}$ and/or more than $20^{\circ}$ sagittal plane rotation at the site of injury on a flexion-extension lateral radiograph was considered to indicate clinical segmental instability. The relationship between cause of injury, segmental instability, and neurological status was also analyzed.

Demographic data were compared between the groups using the Mann-Whitney U-test and the Fisher exact test. The Kruskal-Wallis test was used for pairwise comparisons. Statistical analysis was performed using the JMP 8 program (SAS Institute). $p$ values of $<0.05$ were considered statistically significant.

\section{Results \\ AIS Grade A}

Of the 14 patients with an AIS grade of A who were admitted within 24 hours after injury, 4 (28.6\%) experienced sequential neurological improvement. Spinal reflexes, such as bulbocavernosus reflex or plantar response, were elicited in 12 of the 14 patients at the time of admission. Spinal reflex was elicited at the time of admission in 4 patients who experienced neurological recovery, and 3 of them remained at AIS grade A until 1 week after injury. Three (23.1\%) of the 13 patients with an AIS grade of A who were admitted between 24 and 48 hours after injury and $2(50.0 \%)$ of the 4 patients with an AIS grade A who were admitted between 49 hours and 72 hours after injury experienced sequential neurological improvement (Fig. 1). Of the 31 patients with an AIS grade of A who were admitted within 72 hours after injury, 2 (6.5\%) improved to AIS grade B, 5 (16.1\%) improved to AIS grade
$\mathrm{C}$, and 2 (6.5\%) improved to AIS grade D; the remaining $22(71.0 \%)$ patients experienced no neurological improvement by 6 months after injury (Table 2).

The sequential improvements in the patients who remained at AIS grade A 48 hours (26 patients) or 72 hours (29 patients) after injury were the same as the improvements noted in the patients admitted within 24 hours after injury (Table 3). The $22(71.0 \%)$ patients who remained at AIS grade A 1 month after injury experienced no neurological improvement 6 months after their injury (Fig. 1).

\section{AlS Grade B}

Of the 18 patients with an AIS grade of B who were admitted within 24 hours after injury, including 2 patients considered to have an AIS grade of A at their respective primary institutions, $16(88.9 \%)$ experienced sequential neurological improvement. Of the 6 patients with an AIS grade of B who were admitted between 25 and 48 hours after injury, including 1 patient considered to have an AIS grade of A at the primary institution, 4 (66.7\%) experienced sequential neurological improvement, and of the 7 patients with an AIS grade of B who were admitted between 49 and 72 hours after injury, including 1 patient considered to have an AIS grade A at the primary institution, 7 (100.0\%) experienced sequential neurological improvement (Fig. 2). Of the 31 patients with an AIS grade of B who were admitted within 72 hours after injury, 11 (35.5\%) improved to AIS grade C and 16 (51.6\%) improved to AIS grade D; the remaining 4 (12.9\%) patients showed no neurological improvement 6 months after injury (Table 2).

The sequential observations of at least a 1-grade improvement in the patients who remained at AIS grade B 48 hours (20 patients) or 72 hours (23 patients) after injury were almost the same as the improvements noted in the 18 patients admitted within 24 hours after injury (80.0\%, $82.6 \%$, and $88.9 \%$, respectively). From the perspective of recovery to AIS grade D by 6 months after injury by those admitted with an AIS grade of B within 24, 48, or 72 hours after injury $(40.0 \%, 34.8 \%$, and $55.6 \%$, respectively), it seemed that the longer a patient was at AIS grade B, the lower his or her likelihood of recovery from paralysis (Table 3, Fig. 2).

In addition, based on the modified Frankel grade of $\mathrm{B}$, the extent of recovery to AIS grade D 6 months after injury in patients in subgroup B3 (preservation of the ability to feel a pinprick in segments S4-5) was larger than that in patients in subgroups B1 and B2 (without the ability to feel a pinprick in segments S4-5) (Table 4).

\section{Preexisting Spinal Canal Stenosis}

We found no significant differences in the demographic data, including age, sex, and spinal cord compression at the injury level, among the patients with a baseline AIS grade A or B injury who experienced neurological improvement and those who experienced no improvement (Table 5).

\section{Other}

The relationships between cause of injury, segmental instability, and neurological status are summarized in Table 6. The cause of most of the injuries was a fall on 


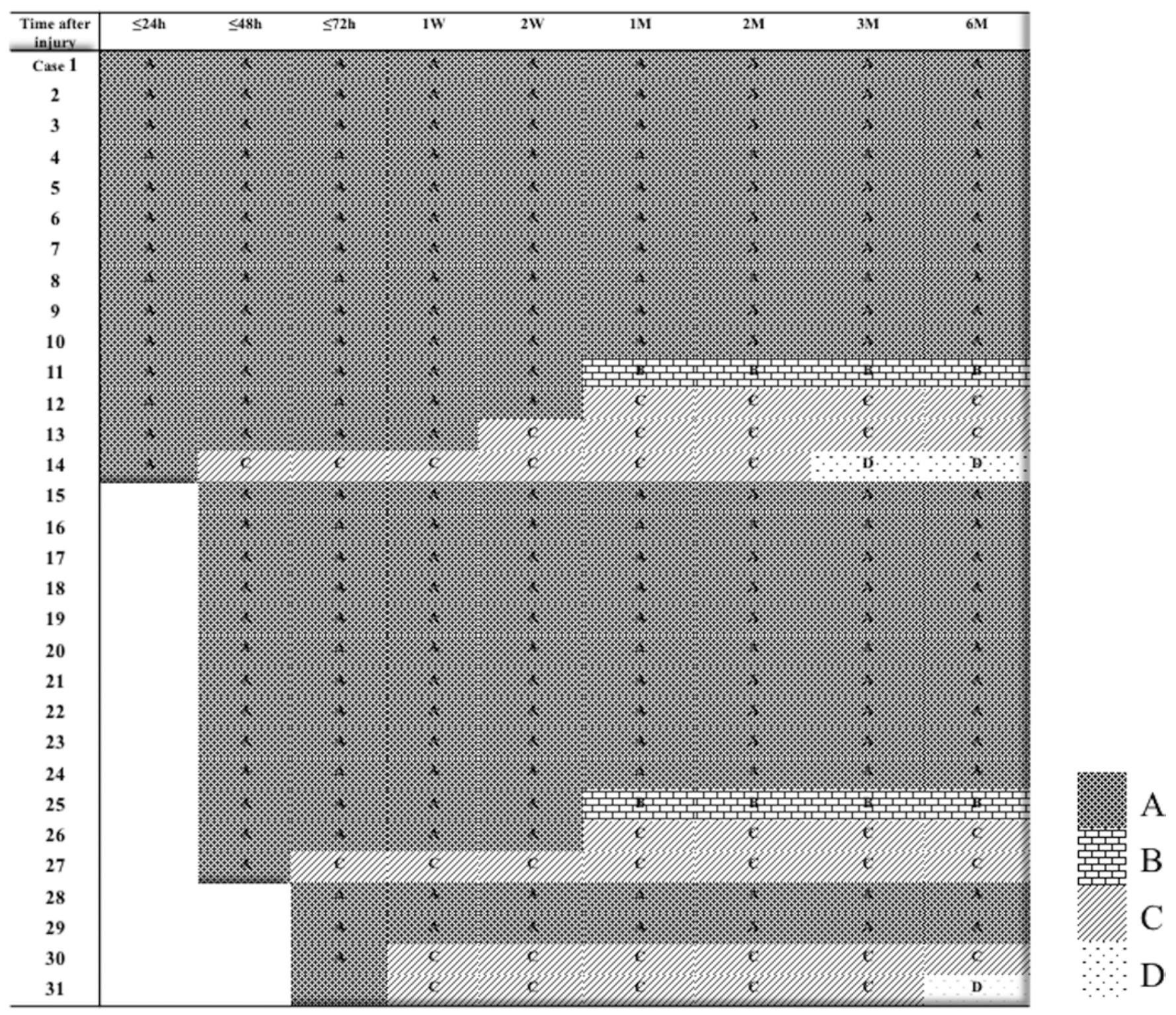

FIG. 1. Sequential changes in AIS grade according to time after injury of the 31 patients at AIS grade A at admission. Nine (29.0\%) patients experienced AIS grade improvement, but the remaining $22(71.0 \%)$ patients had experienced no neurological improvement by 6 months after injury. $h=$ hours; $M=$ months; $W=$ weeks.

level ground or from a height (e.g., a fall from stairs or a stepladder), and extension injury was thought to be the pathomechanism of injury. Segmental instability was seen on a flexion-extension lateral radiograph for $5(8.1 \%)$ of the 62 patients. All of these patients were injured from a fall on level ground, and 4 of them experienced no neurological recovery.

\section{Discussion}

Acute traumatic cervical SCI without bone and disc injury has been described as SCI without radiographic evidence of trauma that is caused by extension injury. ${ }^{19,20 \text {, }}$ 28,29,33-35 Most patients with such an injury are elderly and present with degenerative radiographic findings such as osteophytes, disc bulging/herniation, and hypertrophy of the ligamentum flavum. Cervical SCI caused by extension injury can be subdivided into 2 categories. If a person has cervical spondylosis, sudden neck extension can produce severe cord compression between the bulging ligamentum flavum and the posterior osteophytes of the vertebral body or a bulging disc without any residual radiographic abnormality. ${ }^{29,33}$ The other type of extension injury to the neck is caused when a person suffers a more intense neck extension force, in which SCI takes place by momentary nipping between the posteroinferior border of the posteriorly displaced vertebral body above and the edge of the subjacent lamina..$^{10,34} \mathrm{~A}$ displaced vertebra is usually spontaneously reduced and leaves no or only a subtle radiographic abnormality. ${ }^{34}$ Although we analyzed patients with complete motor paralysis in this study, most patients were injured from a fall on level ground or from a height 
TABLE 2. Sequential changes in AIS grade

\begin{tabular}{cccccc}
\hline \multirow{2}{*}{$\begin{array}{c}\text { AIS Grade at } \\
\text { Admission }\end{array}$} & \multicolumn{5}{c}{ AIS Grade 6 Mos After Injury } \\
\cline { 2 - 5 } & A & B & C & D & Total \\
\hline A & $22(71.0)$ & $2(6.5)$ & $5(16.1)$ & $2(6.5)$ & 31 \\
\hline B & $0(0)$ & $4(12.9)$ & $11(35.5)$ & $16(51.6)$ & 31 \\
\hline
\end{tabular}

Values represent numbers of patients (\%).

(e.g., from stairs or a stepladder), which do not seem to be extremely high-energy traumas. Cervical SCIs without bone and disc injury associated with segmental instability in our study were likely to be caused by the latter pathomechanism (when a patient fell on level ground and a strong pincer impact probably caused severe spinal cord damage).

Whether cervical SCI without bone and disc injury should be treated with surgery or conservative measures remains controversial. ${ }^{3-5,8,15-17,25,27,31,36}$ Our understanding is that cervical SCI without bone and disc injury basically involves no instability; based on our previous treatment experiences, even if it were associated with segmental instability, that instability could be controlled by the patient using a cervical collar for 3-4 weeks after injury. Moreover, even though it is associated with preexisting spinal canal stenosis, the canal stenosis itself might not affect the recovery of the injured spinal cord. ${ }^{16,21,24,26,32}$ Therefore, our principal management strategy for patients with such an injury is conservative treatment. In this study, we found no significant correlation between the degree of spinal cord compression associated with preexisting spinal canal stenosis and neurological improvement. However, in the case of spinal cord compression associated with spinal canal stenosis, surgical decompression can be expected to accelerate the rate of recovery or to improve the level of final neurological function. ${ }^{1,4,9,11,30}$

Kawano et al. ${ }^{16}$ conducted a prospective comparative study of conservative treatment and surgery for cervical SCI without bone and disc injury. They found no difference in neurological improvements between the 2 groups. However, because the mean time between injury and surgery was 8.2 days, it could be argued that if the patients had undergone surgery sooner, they would have experienced greater recovery than the conservative group did. The issue of the timing of surgical intervention is critical when determining the effect of surgery on neurological outcomes. In the acute SCI study (STASCIS), ${ }^{9}$ a multicenter prospective cohort study was performed to evaluate the effectiveness of early $(<24$ hours after injury) versus late ( $\geq 24$ hours after injury) decompression surgery after traumatic cervical SCI. Although the investigators did not report the number of patients included in the study who sustained cervical SCI without bone and disc injury, they concluded that early decompression was associated with improved neurological outcome, defined as at least a 2-grade AIS improvement by the 6-month follow-up. The baseline AIS grade was critical in their evaluation of neurological improvement; a point of interest is whether a great difference in the baseline AIS grades of the 2 groups existed. It is not appropriate to compare their results di-
TABLE 3. Changes in AIS grade according to time after injury

\begin{tabular}{cccccc}
\hline \multirow{2}{*}{$\begin{array}{c}\text { AIS Grade } \\
\text { \& Time } \\
\begin{array}{c}\text { After } \\
\text { Injury (hrs) }\end{array}\end{array}$} & $\begin{array}{c}\text { No. of } \\
\text { Patients } \\
\text { at Each } \\
\text { Postinjury } \\
\text { Time Point }\end{array}$ & A & B & C & D \\
\hline \multicolumn{7}{c}{ A } & & & & & \\
\hline 24 & 14 & $10(71.4)$ & $1(7.1)$ & $2(14.3)$ & $1(7.1)$ \\
\hline 48 & 26 & $20(76.9)$ & $2(7.7)$ & $4(15.4)$ & $0(0.0)$ \\
\hline 72 & 29 & $22(75.9)$ & $2(6.9)$ & $4(13.8)$ & $1(3.4)$ \\
\hline B & & & & & \\
\hline 24 & 18 & $0(0.0)$ & $2(11.1)$ & $6(33.3)$ & $10(55.6)$ \\
\hline 48 & 20 & $0(0.0)$ & $4(20.0)$ & $8(40.0)$ & $8(40.0)$ \\
\hline 72 & 23 & $0(0.0)$ & $4(17.4)$ & $11(47.8)$ & $8(34.8)$ \\
\hline
\end{tabular}

Values represent numbers of patients (\%) unless otherwise indicated.

rectly to our results because of the differences in patient characteristics. However, there seems to be no difference in the results; a 2-grade AIS improvement from a baseline AIS grade of A occurred in $8(18.2 \%)$ of 44 patients in their early-surgery group and in $7(22.6 \%)$ of 31 patients in our conservative treatment group, and the improvement from a baseline AIS grade of B occurred in $14(45.2 \%)$ of 31 patients in their early-surgery group and in $16(51.6 \%)$ of 31 patients in our conservative treatment group. From their systematic review, Lenehan et al. ${ }^{23}$ reported that early surgical decompression ( $<24$ hours) resulted in better neurological outcomes than late surgery for the treatment of acute central cord injury without instability. In their review, only patients with an AIS grade C or D injury were analyzed, and they included only 9 patients with an AIS grade C injury in their early-surgery group (versus 19 patients in their late-surgery group), which might not be a large enough sample from which to draw a conclusion.

In an observational Canadian cohort study with 505 patients who sustained acute traumatic SCI, which included 311 patients with a cervical lesion, patients with an incomplete AIS grade evaluation who underwent surgical treatment within 24 hours after the time of injury experienced better motor recovery improvement than those who had surgery at a time later than 24 hours after injury. ${ }^{6}$ Concurrent spinal cord compression caused by fracture dislocation or other occurrences should be decompressed, and early spinal decompression surgery might produce better neurological improvements. However, the question of whether neurological recovery after SCI is impaired by the asymptomatic preexisting spinal cord compression commonly associated with cervical SCI without bone and disc injury remains. Treatment measures and the timing of surgery for cervical SCI without bone and disc injury must be determined separately from those for cervical SCI caused by fracture dislocation.

In contrast, the authors of a review of surgical interventions in the setting of traumatic central cord syndrome in which the Frankel grade was used reported no difference in motor improvements among patients who did and those who did not undergo surgery within 24 hours after injury. ${ }^{31}$

It is certainly a possibility that the earlier the surgery is 


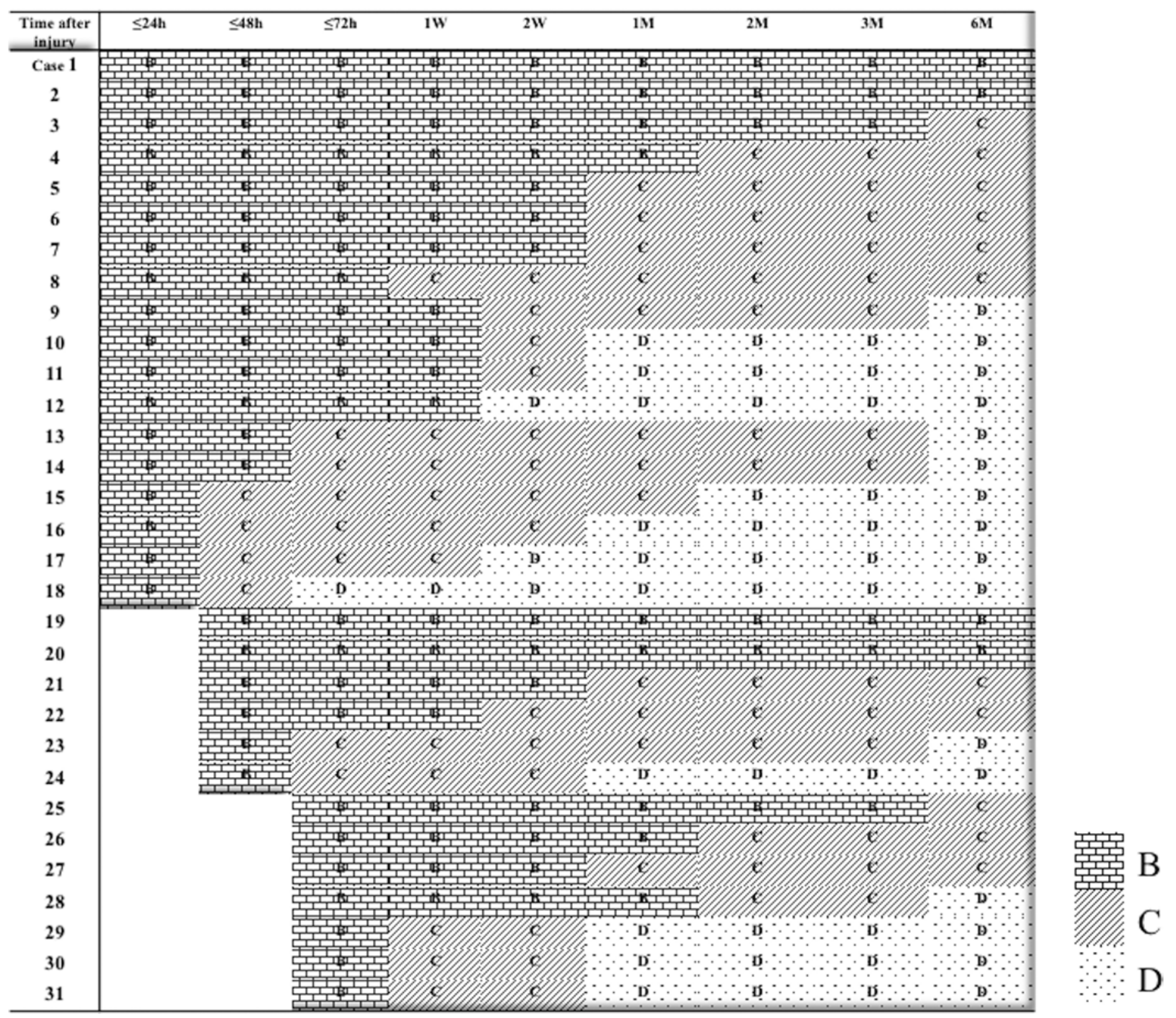

FIG. 2. Sequential changes in AIS grade according to time after injury of the 31 patients at AIS grade B at admission. Twenty-seven (87.1\%) patients experienced an AIS grade improvement, but the remaining 4 (12.9\%) patients had experienced no neurological improvement by 6 months after injury.

performed, the larger the proportion of patients who experience spontaneous recovery after surgery will be. When early surgery for patients with complete motor paralysis (AIS grade A or B) produced good results in the recovery of leg motor palsy, it seemed to be a surgical success. However, some of those patients could have experienced a spontaneous recovery without undergoing surgery. In our study, 1 of the 14 patients with an AIS grade of A and 4 of the 18 patients with an AIS grade of B who were admitted within 24 hours after injury experienced at least a 1-grade AIS improvement within the following 24 hours. Furthermore, among the 24 patients who were transferred from a primary institution with an AIS grade B injury at the time of admission, 2 of the 11 patients who were admitted within 24 hours, 1 of the 6 patients who were ad- mitted between 25 and 48 hours, and 1 of the 7 patients who were admitted between 49 and 72 hours after injury seemed to be considered to have had complete motor and sensory paralysis at their respective primary institutions. Although information about neurological status from the primary doctors was not entirely reliable because of their lack of neurological evaluation training, it is certainly possible that patients recovered from an AIS grade of A immediately after injury to AIS grade B before admission to our hospital. Thus, there were definitively some patients who recovered spontaneously in even the early stage after injury, so physicians should be deliberate in assessing the neurological outcomes of early surgery.

In a historical review, without restricting consideration to those with central cord injury, Fawcett et al. ${ }^{7}$ reported 
TABLE 4. Changes in AIS grade according to time after injury (modified Frankel grade B)

\begin{tabular}{|c|c|c|c|c|}
\hline \multirow{2}{*}{$\begin{array}{l}\text { Modified Frankel } \\
\text { Grade at } \\
\text { Admission \& Time } \\
\text { Postinjury (hrs) }\end{array}$} & \multirow{2}{*}{$\begin{array}{l}\text { No. of Patients } \\
\text { at Each } \\
\text { Postinjury } \\
\text { Time Point }\end{array}$} & \multicolumn{3}{|c|}{ AIS Grade at 6 Mos } \\
\hline & & B & C & $\mathrm{D}$ \\
\hline \multicolumn{5}{|l|}{ B1 } \\
\hline 24 & 9 & $1(11.1)$ & $3(33.3)$ & $5(55.6)$ \\
\hline 48 & 6 & $1(16.7)$ & $2(33.3)$ & $2(33.3)$ \\
\hline 72 & 4 & $1(25.0)$ & $2(50.0)$ & $1(25.0)$ \\
\hline \multicolumn{5}{|l|}{ B2 } \\
\hline 24 & 6 & $1(16.7)$ & $3(50.0)$ & $2(33.3)$ \\
\hline 48 & 11 & $2(18.2)$ & $6(54.5)$ & $3(27.3)$ \\
\hline 72 & 14 & $3(21.4)$ & $8(57.1)$ & $3(21.4)$ \\
\hline \multicolumn{5}{|l|}{ B3 } \\
\hline 24 & 3 & $0(0.0)$ & $0(0.0)$ & $3(100.0)$ \\
\hline 48 & 3 & $0(0.0)$ & $0(0.0)$ & $3(100.0)$ \\
\hline 72 & 5 & $0(0.0)$ & $1(20.0)$ & $4(80.0)$ \\
\hline
\end{tabular}

Values represent numbers of patients (\%) unless otherwise indicated. that $15 \%-25 \%$ of patients who suffered an AIS grade A cervical cord injury had experienced at least a 1-grade spontaneous improvement 1 year after their injury. They also described a certain percentage of AIS grade improvements between the initial examination (within 3 days to 4 weeks after injury) and the 1-year follow-up after cervical or thoracic SCI; namely, the rate of conversion from AIS grade B to C was $15 \%-40 \%$, and the rate of conversion from AIS grade B to D was approximately $40 \%$. In our study, we investigated the extent of recovery after conservative treatment for patients with complete motor paralysis in the setting of acute cervical SCI without bone and disc injury. Approximately $30 \%$ of the 31 patients with an AIS grade of A who were admitted within 72 hours after injury improved, and $23 \%$ of the patients recovered to AIS grade $\mathrm{C}$ or D by 6 months after conservative treatment. Furthermore, even in the 14 patients who were admitted within 24 hours, the same improvement was observed. Instead of experiencing sequential recovery with time, patients with a baseline AIS grade of A who experienced no improvement within 1 month after treatment never improved. This result indicates that the extent of recovery from palsy depends partially on the time required for recovery.

For the 31 patients with an AIS grade B injury who were admitted within 72 hours, recovery was observed

TABLE 5. Population demographics regarding AIS grade improvement

\begin{tabular}{|c|c|c|c|c|c|c|c|}
\hline \multirow{2}{*}{$\begin{array}{l}\text { Baseline AIS } \\
\text { Grade }\end{array}$} & \multirow{2}{*}{$\begin{array}{c}\text { No. of } \\
\text { Patients }\end{array}$} & \multirow{2}{*}{$\begin{array}{c}\text { Mean } \\
\text { Age (yrs) }\end{array}$} & \multirow{2}{*}{$\begin{array}{l}\text { Sex }(M / F) \\
\text { Ratio }\end{array}$} & \multicolumn{3}{|c|}{ Admission Time After Injury (hrs) } & \multirow{2}{*}{$\begin{array}{c}\text { Spinal Cord } \\
\text { Compression Rate }(\%)^{*}\end{array}$} \\
\hline & & & & $<24$ & $24-48$ & $49-72$ & \\
\hline \multicolumn{8}{|l|}{ A } \\
\hline Improved & 9 & 65.8 & $7: 2$ & 4 & 3 & 2 & $31.3 \pm 12.3$ \\
\hline Not improved & 22 & 67.7 & $19: 3$ & 10 & 10 & 2 & $36.1 \pm 16.1$ \\
\hline$p$ value & & NS & NS & NS & & & NS \\
\hline \multicolumn{8}{|l|}{$\mathrm{B}$} \\
\hline Improved & 27 & 64.4 & $24: 3$ & 16 & 4 & 7 & $27.8 \pm 13.9$ \\
\hline Not improved & 4 & 63.5 & $4: 0$ & 2 & 2 & 0 & $40.6 \pm 8.6$ \\
\hline$p$ value & & NS & NS & NS & & & 0.077 \\
\hline
\end{tabular}

NS = not significant.

Values represent numbers of patients unless otherwise indicated.

* Values are presented as the mean \pm SD.

TABLE 6. Relationships between cause of injury, segmental instability, and neurological status in 62 patients with extension injury

\begin{tabular}{|c|c|c|c|c|c|c|c|}
\hline \multirow[b]{2}{*}{ Cause of Injury } & \multirow{2}{*}{$\begin{array}{c}\text { No. of } \\
\text { Patients }\end{array}$} & \multirow[b]{2}{*}{ Segmental Instability } & \multirow{2}{*}{$\begin{array}{c}\text { No. of } \\
\text { Patients }\end{array}$} & \multicolumn{2}{|c|}{ Baseline AIS Grade $A^{*}$} & \multicolumn{2}{|c|}{ Baseline AIS Grade B } \\
\hline & & & & + & - & + & - \\
\hline \multirow[t]{2}{*}{ Fall on level ground } & \multirow[t]{2}{*}{27} & Yes & 5 & 1 & 3 & 0 & 1 \\
\hline & & No & 22 & 3 & 6 & 12 & 1 \\
\hline \multirow[t]{2}{*}{ Fall from a height } & \multirow[t]{2}{*}{25} & Yes & 0 & 0 & 0 & 0 & 0 \\
\hline & & No & 25 & 5 & 8 & 11 & 1 \\
\hline \multirow[t]{2}{*}{ Traffic accident } & \multirow[t]{2}{*}{10} & Yes & 0 & 0 & 0 & 0 & 0 \\
\hline & & No & 10 & 0 & 5 & 4 & 1 \\
\hline
\end{tabular}

+ = AIS grade improvement; - = no AIS grade improvement.

* Values are numbers of patients. 
with time. Approximately $85 \%$ of the patients improved, and almost half of the patients recovered to AIS grade D by 6 months after conservative treatment. According to the modified Frankel grade of B, the neurological improvement in patients graded at B3 (preservation of the ability to feel a pinprick in sacral segments $\mathrm{S} 4-5$ ) was better than that in the patients graded B1 or B2 (without the ability to feel a pinprick in sacral segments S4-5). Even though the patients remained at grade B3 72 hours after injury, $80 \%$ of them recovered to AIS grade D by 6 months after conservative treatment. One of the reasons for this phenomenon might be anatomical characteristics; the sacral segments within the lateral spinothalamic tract are located close to the corticospinal tract in the spinal cord. Although recovery from palsy would be expected to be observed sequentially throughout follow-up, the longer a patient remained at grade B (either AIS or modified Frankel), the less the extent of neurological recovery tended to be. This finding indicates that the time required for neurological recovery influences the level of recovery. In fact, sequential neurological improvement from paralysis caused by acute cervical SCI can be observed even in patients with complete motor paralysis (AIS grade A or B). Especially in the case of patients with a grade B injury, the degree of neurological improvement is likely to be better because their paralysis is incomplete.

We recognize that neurological recovery occurs after both surgical and conservative treatment, and the matter of concern is which strategy produces better neurological outcomes. This study had some limitations. We could not evaluate the accuracy of neurological status immediately after injury in most of the patients because our hospital is not an emergency medical center capable of accommodating a patient who is transferred directly from an accident scene. We are unable to deny the possibility that, among those who were diagnosed as being at AIS grade A or B at the time of our hospital admission, some patients could have had voluntary leg motion at the primary institution; this is a weak point in the study. Most patients who had segmental instability experienced no neurological recovery, and the effect that surgical stabilization would have had on those patients is also unclear. Also, ours was a small retrospective study that used only AIS grading, and a large group of surgically treated patients was not included. A prospective randomized study with a large sample size is required to compare the outcomes of patients who undergo conservative management with those who undergo surgical treatment.

\section{Conclusions}

Sequential neurological improvements after conservative treatment were observed in patients with complete motor paralysis within 72 hours from cervical SCI without bone and disc injury. Approximately $30 \%$ of the patients with a baseline AIS grade of A improved, and 7\% of these patients recovered to AIS grade D. Approximately $85 \%$ of the patients with a baseline AIS grade of B improved, and $50 \%$ of these patients recovered to AIS grade D by 6 months after conservative treatment. It is very important to recognize the extent of neurological improvement that is possible even after conservative treatment for severe complete motor paralysis. Physicians should be cautious about having an automatic preference for surgical intervention, especially early surgery, before appropriate prospective control studies can prove the superiority of surgical treatment in attaining neurological improvement.

\section{References}

1. Aarabi B, Alexander M, Mirvis SE, Shanmuganathan K, Chesler D, Maulucci C, et al: Predictors of outcome in acute traumatic central cord syndrome due to spinal stenosis. J Neurosurg Spine 14:122-130, 2011

2. Brandenstein D, Molinari RW, Rubery PT, Rechtine GR II: Unstable subaxial cervical spine injury with normal computed tomography and magnetic resonance initial imaging studies: a report of four cases and review of the literature. Spine (Phila Pa 1976) 34:E743-E750, 2009

3. Brodell DW, Jain A, Elfar JC, Mesfin A: National trends in the management of central cord syndrome: an analysis of 16,134 patients. Spine J 15:435-442, 2015

4. Chen TY, Dickman CA, Eleraky M, Sonntag VK: The role of decompression for acute incomplete cervical spinal cord injury in cervical spondylosis. Spine (Phila Pa 1976) 23:2398-2403, 1998

5. Donovan WH: Operative and nonoperative management of spinal cord injury. A review. Paraplegia 32:375-388, 1994

6. Dvorak MF, Noonan VK, Fallah N, Fisher CG, Finkelstein J, Kwon BK, et al: The influence of time from injury to surgery on motor recovery and length of hospital stay in acute traumatic spinal cord injury: an observational Canadian cohort study. J Neurotrauma 32:645-654, 2015

7. Fawcett JW, Curt A, Steeves JD, Coleman WP, Tuszynski $\mathrm{MH}$, Lammertse D, et al: Guidelines for the conduct of clinical trials for spinal cord injury as developed by the ICCP panel: spontaneous recovery after spinal cord injury and statistical power needed for therapeutic clinical trials. Spinal Cord 45:190-205, 2007

8. Fehlings MG, Perrin RG: The timing of surgical intervention in the treatment of spinal cord injury: a systematic review of recent clinical evidence. Spine (Phila Pa 1976) 31 (11 Suppl):S28-S36, 2006

9. Fehlings MG, Vaccaro A, Wilson JR, Singh A, W Cadotte D, Harrop JS, et al: Early versus delayed decompression for traumatic cervical spinal cord injury: results of the Surgical Timing in Acute Spinal Cord Injury Study (STASCIS). PLoS One 7:e32037, 2012

10. Forsyth HF: Extension injuries of the cervical spine. J Bone Joint Surg Am 46:1792-1797, 1964

11. Gu Y, Chen L, Dong RB, Feng Y, Yang HL, Tang TS: Laminoplasty versus conservative treatment for acute cervical spinal cord injury caused by ossification of the posterior longitudinal ligament after minor trauma. Spine J 14:344-352, 2014

12. Guest J, Eleraky MA, Apostolides PJ, Dickman CA, Sonntag VK: Traumatic central cord syndrome: results of surgical management. J Neurosurg 97 (1 Suppl):25-32, 2002

13. Hardy AG: Cervical spinal cord injury without bony injury. Paraplegia 14:296-305, 1977

14. Hayashi T, Kawano O, Sakai H, Ideta R, Ueta T, Maeda T, et al: The potential for functional recovery of upper extremity function following cervical spinal cord injury without major bone injury. Spinal Cord 51:819-822, 2013

15. Katoh S, el Masry WS, Jaffray D, McCall IW, Eisenstein SM, Pringle RG, et al: Neurologic outcome in conservatively treated patients with incomplete closed traumatic cervical spinal cord injuries. Spine (Phila Pa 1976) 21:2345-2351, 1996 
16. Kawano O, Ueta T, Shiba K, Iwamoto Y: Outcome of decompression surgery for cervical spinal cord injury without bone and disc injury in patients with spinal cord compression: a multicenter prospective study. Spinal Cord 48:548-553, 2010

17. Kepler CK, Kong C, Schroeder GD, Hjelm N, Sayadipour A, Vaccaro AR, et al: Early outcome and predictors of early outcome in patients treated surgically for central cord syndrome. J Neurosurg Spine 23:490-494, 2015

18. Kirshblum SC, Burns SP, Biering-Sorensen F, Donovan W, Graves DE, Jha A, et al: International standards for neurological classification of spinal cord injury (revised 2011). J Spinal Cord Med 34:535-546, 2011

19. Kothari P, Freeman B, Grevitt M, Kerslake R: Injury to the spinal cord without radiological abnormality (SCIWORA) in adults. J Bone Joint Surg Br 82:1034-1037, 2000

20. Koyanagi I, Iwasaki Y, Hida K, Akino M, Imamura H, Abe $\mathrm{H}$ : Acute cervical cord injury without fracture or dislocation of the spinal column. J Neurosurg 93 (1 Suppl):15-20, 2000

21. Kubota K, Saiwai H, Kumamaru H, Kobayakawa K, Maeda T, Matsumoto Y, et al: Neurological recovery is impaired by concurrent but not by asymptomatic pre-existing spinal cord compression after traumatic spinal cord injury. Spine (Phila Pa 1976) 37:1448-1455, 2012

22. La Rosa G, Conti A, Cardali S, Cacciola F, Tomasello F: Does early decompression improve neurological outcome of spinal cord injured patients? Appraisal of the literature using a meta-analytical approach. Spinal Cord 42:503-512, 2004

23. Lenehan B, Fisher CG, Vaccaro A, Fehlings M, Aarabi B, Dvorak MF: The urgency of surgical decompression in acute central cord injuries with spondylosis and without instability. Spine (Phila Pa 1976) 35 (21 Suppl):S180-S186, 2010

24. Maeda T, Ueta T, Mori E, Yugue I, Kawano O, Takao T, et al: Soft-tissue damage and segmental instability in adult patients with cervical spinal cord injury without major bone injury. Spine (Phila Pa 1976) 37:E1560-E1566, 2012

25. Mazaki T, Ito Y, Sugimoto Y, Koshimune K, Tanaka M, Ozaki T: Does laminoplasty really improve neurological status in patients with cervical spinal cord injury without bone and disc injury? A prospective study about neurological recovery and early complications. Arch Orthop Trauma Surg 133:1401-1405, 2013

26. Okada S, Maeda T, Ohkawa Y, Harimaya K, Saiwai H, Kumamaru H, et al: Does ossification of the posterior longitudinal ligament affect the neurological outcome after traumatic cervical cord injury? Spine (Phila Pa 1976) 34:1148-1152, 2009

27. Pollard ME, Apple DF: Factors associated with improved neurologic outcomes in patients with incomplete tetraplegia. Spine (Phila Pa 1976) 28:33-39, 2003

28. Saruhashi Y, Hukuda S, Katsuura A, Asajima S, Omura K: Clinical outcomes of cervical spinal cord injuries without radiographic evidence of trauma. Spinal Cord 36:567-573, 1998

29. Schneider RC, Cherry G, Pantek H: The syndrome of acute central cervical spinal cord injury; with special reference to the mechanisms involved in hyperextension injuries of cervical spine. J Neurosurg 11:546-577, 1954

30. Song J, Mizuno J, Nakagawa H, Inoue T: Surgery for acute subaxial traumatic central cord syndrome without fracture or dislocation. J Clin Neurosci 12:438-443, 2005

31. Stevens EA, Marsh R, Wilson JA, Sweasey TA, Branch CL $\mathrm{Jr}$, Powers AK: A review of surgical intervention in the setting of traumatic central cord syndrome. Spine J 10:874880,2010

32. Takao T, Morishita Y, Okada S, Maeda T, Katoh F, Ueta T, et al: Clinical relationship between cervical spinal canal stenosis and traumatic cervical spinal cord injury without major fracture or dislocation. Eur Spine J 22:2228-2231, 2013

33. Taylor AR: The mechanism of injury to the spinal cord in the neck without damage to vertebral column. J Bone Joint Surg Br 33-B:543-547, 1951

34. Taylor AR, Blackwood W: Paraplegia in hyperextension cervical injuries with normal radiographic appearances. J Bone Joint Surg Br 30B:245-248, 1948

35. Tewari MK, Gifti DS, Singh P, Khosla VK, Mathuriya SN, Gupta SK, et al: Diagnosis and prognostication of adult spinal cord injury without radiographic abnormality using magnetic resonance imaging: analysis of 40 patients. Surg Neurol 63:204-209, 2005

36. Vaccaro AR, Daugherty RJ, Sheehan TP, Dante SJ, Cotler JM, Balderston RA, et al: Neurologic outcome of early versus late surgery for cervical spinal cord injury. Spine (Phila Pa 1976) 22:2609-2613, 1997

37. White AA III, Johnson RM, Panjabi MM, Southwick WO: Biomechanical analysis of clinical stability in the cervical spine. Clin Orthop Relat Res 109:85-96, 1975

\section{Disclosures}

The authors report no conflict of interest concerning the materials or methods used in this study or the findings specified in this paper.

\section{Author Contributions}

Conception and design: Mori, Kawano. Acquisition of data: Mori, Ueta, Maeda, Ideta, Yugué, Kawano. Analysis and interpretation of data: Mori, Kawano. Drafting the article: Mori. Critically revising the article: Ueta, Kawano, Shiba. Reviewed submitted version of manuscript: all authors. Approved the final version of the manuscript on behalf of all authors: Mori. Statistical analysis: Mori, Yugué. Administrative/technical/material support: Shiba. Study supervision: Shiba.

\section{Correspondence}

Eiji Mori: Spinal Injuries Center, Japan Organization of Occupational Health and Safety, Fukuoka, Japan. eijimori@orange.ocn. ne.jp. 